\title{
Prevalence of maxillofacial traumas in a hospital of the interior of Brazil
}

\begin{abstract}
Objective: to retrospectively evaluate epidemiological data of maxillofacial trauma at Santa Casa de Caridade de Diamantina hospital, for five years.

Methods: this is a cross-sectional study, performed with recorded data. The collected variables were: age, gender, skin color, type and etiology of trauma, city of origin, and performed procedures. Statistical analyses were performed considering a $5 \%$ significance level.

Results: a total of 236 admissions were found, 213 men and 23 women. The age ranged from 1 to 82 years. Motorcycle accident was the most frequent cause of trauma $(p<0.001)$ and more prevalent in men $(\mathrm{p}=0.01954)$. The treatment of multiple facial fractures was the most frequent (54.7\%). Diamantina was the most representative city (20.3\%).

Conclusion: gender and young-adult population were important factors related to oral and maxillofacial trauma. Motorcycle accident was the most common cause and multiple maxillofacial fractures were the most common consequences.
\end{abstract}

Keywords: wounds and injuries, face, oral surgery, epidemiology, maxillofacial injuries, trauma centers, penetrating head trauma
Volume 7 Issue 6 - 2017

\author{
Brennda Let cia Andrade Almeida Carvalho,' \\ Ren nia Sanches da Silva,' Endi Lanza \\ Galvao, ${ }^{2}$ Ighor Andrade Fernandes,' Saulo \\ Gabriel Moreira Falci, ${ }^{1,3}$ Cassio Roberto \\ Rocha dos Santos' \\ 'Department of Dentistry, Federal University of Jequitinhonha \\ and Mucuri Valleys, Brazil \\ ${ }^{2}$ René Rachou Research Center, Oswaldo Cruz Foundation, \\ Brazil \\ ${ }^{3}$ Department of Oral and Maxillofacial Surgery, Santa Casa de \\ Caridade de Diamantina Hospital, Brazil
}

\section{Correspondence: Saulo Gabriel Moreira Falci, Federal University of Jequitinhonha and Mucuri Valleys, Tiradentes st., 195, Diamantina, Minas Gerais , Brazil, Tel 5538 3532- 6000, Fax 553888 I7 1454, Email saulofalci@hotmail.com}

Received: July 31, 2017 | Published: August 10, 2017

\section{Introduction}

Despite important advances in the prevention and treatment of physical trauma, the course of life of millions of people keeps changing every year. ${ }^{1}$ Among a variety of types of trauma, the maxillofacial trauma stands out because of its importance, since it may cause aesthetic disfiguration and functional disabilities, besides physical damages ${ }^{2}$ with emotional repercussions and the possibility of permanent deformities. ${ }^{3}$ In Brazil, the maxillofacial traumas have a strong impact on society, mainly due to its high rates of morbidity and mortality. As it mainly affects the young and economically active age groups, the financial and social cost is significant, besides the resources involved in the treatment of these patients. ${ }^{4}$ Therefore, facial trauma is considered a public health problem, related to social, cultural, and economic factors, according to data from the World Health Organization (WHO). The incidence of oral and maxillofacial injuries can be related to geographic region, time, temporal, and climatic influences. ${ }^{5}$ In addition, characteristics of the studied population, such as gender, age, alcohol and drug use, domestic violence, and clinical conditions like osteoporosis are other factors that should be considered when evaluating the epidemiology of facial traumas. ${ }^{6-8}$ Although there is a large amount of available literature on the epidemiology of facial trauma, the importance of establishing the characteristics related to its occurrence in specific regions has already been highlighted. Thereby, the Jequitinhonha valley, for being a region of recognized health inequality and socioeconomic aggravating factors in the interior of the state of Minas Gerais, Brazil, represents a relevant object of study. Thus, the aim of this study is to evaluate the epidemiological data of patients with maxillofacial trauma treated at the Santa Casa de Caridade de Diamantina hospital, a reference medical center in treating facial traumas in the region, for a period of five years, enabling better public health planning by the responsible authorities of this locality.

\section{Materials and methods}

This is a retrospective study, performed with data obtained from the review of all medical records of patients who were victims of maxillofacial trauma hospitalized at the Santa Casa de Caridade de Diamantina hospital, between January 2010 and December 2015. The excluded medical records were those presenting inconsistent information and not within the given period. The collected variables were: age, gender, skin color, maxillofacial trauma type, trauma etiology, patient's city of origin, and procedures to treat the injuries. Age was categorized according to the phases of growth to allow better demographic characterization: childhood ( 2 to 10 years), adolescence (11 to 17 years), young adult (18 to 40 years), adult (41 to 65 years), and elderly (> 65 years). ${ }^{9}$ The city of origin was also categorized according to the distance travelled by the patient to the hospital: up to $30 \mathrm{~km}$; between 31 and $100 \mathrm{~km}$, and over $100 \mathrm{~km}$. For this, we used the Google Maps, available for free on the internet. All data were tabulated in a spreadsheet of the Microsoft Office Excel 2010 and analyzed using the Statistical Package for Social Science (SPSS) program, version 22.0. The absolute and percentage frequencies were obtained (descriptive statistics techniques) and the Pearson's Chi-square test was used to compare the variables, when applicable. The level of significance used in the statistical tests was $5 \%(\mathrm{p}<0.05)$. The project that preceded this research followed the recommendations of the 466/12 resolution of the National Health Council (CNS), previously submitted for analysis and approved by 
the Ethics and Research Committee (CEP) of the Federal University of Jequitinhonha and Mucuri Valleys (UFVJM). The received protocol number of approval was 1.605.020.

\section{Results}

From January 2010 to December 2015, the Santa Casa de Caridade de Diamantina hospital executed 236 hospitalizations due to maxillofacial trauma, of which 213 were men $(90.3 \%)$ and 23 were women $(9.7 \%)$. Regarding age, it ranged from 1 to 82 years, with a mean of 29.8 years $(S D=13.9)$ for men and 33.1 years $(S D=20.6)$ for women. Table 1 shows the distribution of patients in relation to the age group at the time of the trauma. Among the causes of trauma, motorcycle accident was the most frequent $(36.0 \%)$, followed by fall $(14.8 \%)$, being this difference statistically significant $(\mathrm{p}<0.001)$. Maxillofacial trauma due to motorcycle accident was more prevalent in men $(39.4 \%)$ than in women $(4.3 \%)(p=0.01954)$. There was no association between gender and the other categories of trauma etiology. Figure 1A shows the distribution of the causes that led the patients to maxillofacial trauma. The treatment to reduce multiple fractures of the face was the most frequent, being performed in 54.7\% of the cases. The second most common procedure was the treatment to reduce mandibular fracture $(25.8 \%)$. The other procedures performed are described in figure 1B. For both genders, the treatment for multiple facial fractures prevailed (men: $54.9 \%$; women: $52.2 \%$ ), and this association was not statistically significant. There was a predominance of treatment of soft tissue injuries in women $(34.8 \%)$ when compared to men $(5.6 \%)(p<0.001)$. When analyzing the time and the distribution of hospitalizations for treatment of facial traumas, there is a greater occurrence of cases in the year of 2014. The months of August, October and June were highlighted by the higher incidence of traumas, as can be observed in figure 1C. Regarding to self-reported skin color, there were 190 cases of brown individuals $(80.5 \%), 44$ cases of white individuals (18.6\%), and 2 cases of black individuals $(0.8 \%)$. No patient declared himself as yellow or from indigenous origin. The city of origin of the patients was quite diverse, being evaluated patients from 43 cities of the state of Minas Gerais, one from Espírito Santo state, and one from São Paulo state. The city with the highest number of cases was Diamantina, in Minas Gerais, with 48 patients $(20.3 \%)$. Table 2 shows the distribution of patients according to the distance travelled from their city of origin to the hospital where they were hospitalized.

Table I Distribution of patients in relation to the age group at the time of the trauma

\begin{tabular}{llll}
\hline Age group & Gender & & Total (\%) \\
\hline & Female (\%) & Male (\%) & \\
\hline $\begin{array}{l}\text { Childhood (0 to I0 } \\
\text { years) }\end{array}$ & $2(8.7)$ & $9(4.2)$ & 1 I (4.7) \\
$\begin{array}{l}\text { Adolescence (II to I7 } \\
\text { years) }\end{array}$ & $7(30.4)$ & $14(6.6)$ & 2 I (8.9) \\
$\begin{array}{l}\text { Young adult (I8 to } 40 \\
\text { years) }\end{array}$ & $6(26.1)$ & $153(7 \mid .8)$ & $159(67.4)$ \\
$\begin{array}{l}\text { Adult (4I to 65 years) } \\
\text { Elderly (>65 years) }\end{array}$ & $6(26.1)$ & $33(15.5)$ & $39(16.5)$ \\
Total & $23(100)$ & $213(100)$ & $236(100)$ \\
\hline
\end{tabular}

Table 2 Distribution of patients in relation to the travelled distance from the city of origin to the hospital

\begin{tabular}{lll}
\hline Travelled distance & Frequency & $\%$ \\
\hline Up to $30 \mathrm{~km}$ & 47 & 19.9 \\
Between 31 and $100 \mathrm{~km}$ & 56 & 23.7 \\
Greater than $100 \mathrm{~km}$ & 133 & 56.4 \\
Total & 236 & 100.0 \\
\hline
\end{tabular}

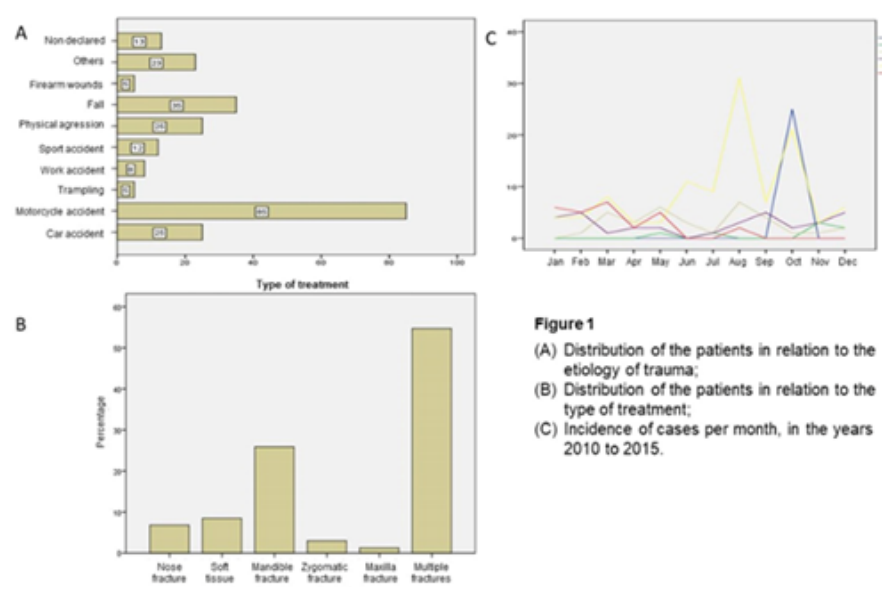

Figure I (A) Distribution of the patients in relation to the etiology of trauma. (B) Distribution of the patients in relation to the type of treatment. (C) Incidence of cases per month, in the years 2010 to 2015.

\section{Motorcycle accidents}

The majority of motorcycle accident cases occurred among young adults aged between 18 and 40 years $(60.0 \%)$, with 47 cases $(55.3 \%)$ resulting in multiple fractures of the face. Likewise, most of these accidents resulting in facial trauma occurred at a distance of more than $100 \mathrm{~km}$ from the hospital $(61.2 \%)$, while $21.2 \%$ occurred at a distance of less than $30 \mathrm{~km}$. A total of $41.2 \%$ of the motorcycle accidents with facial trauma occurred in the year of 2014 with subsequent decrease to $11.8 \%$ in the year of 2015 .

\section{Fall}

$71.4 \%$ of the falls resulting in facial traumas occurred in the economically active population, ranging from 18 to 40 years old, and $48.6 \%$ of those traumas were multiple fractures of the face. Men represented $88.6 \%$ of the fall cases and women $11.4 \%$. Treatment of zygomatic bone fracture by fall occurred in only one case.

\section{Interpersonal violence}

The interpersonal violence, including trauma by firearm and by physical aggressions, was restricted to men in all cases. One patient, a victim of gunshot wounds, presented a mandibular fracture while the others suffered multiple fractures of the face (80\%). Regarding physical aggression, $60 \%$ culminated in multiple fractures of the face, $20 \%$ in mandibular fracture, and $8 \%$ in fracture of the nasal bones.

\section{Trampling}

Only men victim of runover by vehicles had facial trauma. The most involved age group was 18 to 40 years, with three cases $(60 \%)$. The majority of the trampling resulting in facial trauma occurred in 
cities distant more than $100 \mathrm{~km}$ from Diamantina (80\%), where the hospital is located.

\section{Sport accidents}

Women suffered sports accidents resulting in facial trauma in $16.7 \%$ of the cases while men in $83.3 \%$. In $58.3 \%$ of the hospitalizations due to sports practice, the distance travelled by the patient to the hospital was between 31 and $100 \mathrm{~km}$ and in $33 \%$ this distance was greater than $100 \mathrm{~km}$. One event resulted in a fracture of the zygomatic bone and one in the maxilla; $58.3 \%$ of the trauma required treatment for multiple facial fractures and $25 \%$ for mandibular fracture.

\section{Discussion}

The results showed that the highest prevalence of facial trauma is in men, as shown in other studies..$^{2-12}$ The most affected age group was 18 to 40 years (young adult stage), corresponding to $67.4 \%$. This same pattern was observed by Carvalho et al. ${ }^{10}$ who verified $69.9 \%$ of face trauma occurrence in this same age group. The motorcycle accidents were an important mechanism of trauma, accounting for $36 \%$ of victims of facial trauma in the Jequitinhonha valley. Motorcycle accidents as cause of facial trauma were also the most prevalent in the study by Silva et al. ${ }^{11}$ being responsible for $44 \%$ of all cases. However, the literature has reported a gradual change in the etiology of facial fractures, with interpersonal violence overcoming the vehicles accident as the most common cause..$^{3-15}$ Although in recent years many traffic policies have been instituted aiming a greater safety in public roads, ${ }^{16}$ many laws, such as the compulsory use of helmets and driver's licenses, are not respected in small towns that prevail in the Jequitinhonha valley. More stringent supervisions in favor of transit legislation as well as social education activities with an appeal to morbidities related to vehicles accidents can help to minimize the trauma caused by these mechanisms. The distribution of hospitalizations due to facial trauma according to the month of occurrence in the Santa Casa de Caridade de Diamantina hospital followed the same pattern of a study conducted in the city of Uberlândia, in Minas Gerais state, which evidenced the month of August as the month of highest incidence. ${ }^{17}$ The year of 2014 was highlighted by the number of patients hospitalized for treatment of maxillofacial fractures in the Santa Casa de Caridade de Diamantina hospital, with a higher demand in the second semester. The month of May of that year was marked by the implementation of dental care services with the use of general anesthesia or sedation at the referenced hospital, with from the Minas Gerais state government (CIB-SUS/MG Deliberation no 1.844, from May 21st of 2014). ${ }^{18}$ It should be recognized that the increase in admission for facial trauma in the year of 2014 may be related to the improvement of care and access of the population to a referral center with surgery and maxillofacial traumatology specialized professionals. Public health policies such as this can improve the efficacy of health care at the city of origin of the patients, avoiding the necessity to travel long distances looking for treatment and ensuring the integrality of care. The region of origin of the victims of facial trauma treated at the Santa Casa de Caridade de Diamantina hospital elucidates the importance that this institution takes in the interior of the state of Minas Gerais, especially for the Jequitinhonha valley. The hospital met the demand for hospitalization of 45 cities, with $20.3 \%$ of this representative demand of the resident population of Diamantina and the remaining $79.7 \%$ coming from other cities. Considering that the city of Diamantina is the center pole of the Jequitinhonha Expanded Health Region, being then reference for 24 cities, it is verified that it is fulfilling well its role in the regionalization of health. The percentage of treatment for multiple facial fractures was higher than the other procedures $(54.7 \%)$, even than the single mandible fractures that are mentioned by some authors as the most prevalent. ${ }^{2-18}$ The treatment of simple facial fractures was reported by Montovani et al. ${ }^{6}$ in $72.3 \%$ of the cases in a study conducted in the interior of the state of São Paulo. This fact highlights the greater severity of cases of facial trauma in the Jequitinhonha valley. Soft tissue lesions were the most frequent causes of hospitalization among women, suggesting less severity and fewer physical sequelae. ${ }^{11}$ In relation to the skin color group, the results of this study may be presenting an underestimation of the black people as a result of inaccuracy of hospital records. The investigation of ethnicracial inequalities has encountered methodological failures in several studies and the validity of their self-referenced measurement has been discussed. Therefore, a limitation of this study is related to the use of medical records, which may eventually present sub-notifications. Due to this lack of standardization in the hospital records, other relevant variables to the epidemiological characterization of facial trauma in the region were not contemplated by the study. Thus, it is worth emphasizing the importance of the correct and complete filling of medical records by all the healthcare team responsible for the patient care. Despite the limitations, the results of this study may help in the upward planning of health policies, which, despite being provided by the Organic Health Law (8080/90 Law), is not yet a reality.

\section{Conclusion}

In the Jequitinhonha valley, gender is an important factor related to maxillofacial trauma, being the adult-young population the most affected. The most frequent type of trauma was multiple facial fractures and the greatest trauma mechanism in the region was motorcycle accident.

\section{Funding}

None.

\section{Acknowledgements}

Special thanks to FAPEMIG (Foundation for Research Support of Minas Gerais) for the granting of a $\mathrm{PhD}$ scholarship, linked to the Graduate Program in Collective Health of the Rene Rachou Research Center, Oswaldo Cruz Foundation.

\section{Conflicts of interest}

There is no conflict of interest.

\section{References}

1. Peden M. Global collaboration on road traffic injury prevention. Int J Inj Contr Saf Promot. 2005;(12):85-91.

2. Silva JJL, Lima AAAS Melo IFS, Maia RCL, et al. Facial trauma: analysis of 194 cases. Rev Bras Cir Plast. 2011;(26):37-41.

3. Macedo JLS, Camargo LM, Almeida PG, et al. Epidemiology of facial trauma of patients admitted to a public hospital emergency department. Rev Col Bras Cir. 2008;35(1):9-13.

4. Pacella SJ. The financial impacto of facial trauma care: examining the whole picture. Plast Reconstr Surg. 2008;122(5):1586.

5. Kruger E, Tennant M. Fractures of the mandible and maxilla: A 10-year analysis. Australas Med J. 2016;9(1):17-24. 
6. Montovani JC, Campos LMP, Gomes MA, et al. Etiologia e incidência das fraturas faciais em adultos e crianças: experiência em 513 casos. Rev Bras Otorrinolaringol. 2006;72(2):235-241.

7. Samieirad S, Tohidi E, Shahidi-Payam A, et al. Retrospective study maxillofacial fractures epidemiology and treatment plans in Southeast of Iran. Med Oral Patol Oral Cir Bucal. 2015;20(6):e729-e736.

8. Zhou H, Lv K, Yang R, et al. Mechanics in the Production of Mandibular Fractures: A Clinical, Retrospective Case Control Study. PLoS One. 2016;11(2):e0149553.

9. Wulkan M, Parreira JR JG, Botter DA. Epidemiologia do trauma facial. Rev Assoc Med Bras. 2005;51(5):290-295.

10. Carvalho TBO, Cancian LRL, Marques CG, et al. Six years of facial trauma care: an epidemiological analysis of 355 cases. Braz J Otorhinolaryngol. 2010;76(5):565-574.

11. Silva CJP, Ferreira RC, Paula LPP, et al. Maxillofacial injuries as markers of urban violence a comparative analysis between the genders. Cien Saude Colet. 2014;19(1):127-136.

12. Latifi H. Prevalence of Different Kinds of Maxillofacial Fractures and Their Associated Factors Are Surveyed in Patients. Glob J Health Sci. 2014;6(7 Spec No):66-73.
13. Sojat AJ, Meisami T, Sàndor GKB, et al. The Epidemiology of Mandibular Fractures Treated at the Toronto General Hospital: A Review of 246 Cases. J Can Dent Assoc. 2001;67(11):640-644.

14. Tino MT, Andrade FA, Gonçalves AJ, et al. Epidemiology of maxillofacial trauma in a tertiary university hospital of São Paulo city. Rev Bras Cir Cabeça Pescoço. 2010;39(2):139-145.

15. O’Meara C, Witherspoon R, Hapangama N, et al. Mandible fracture severity may be increased by alcohol and interpersonal violence. Aust Dent J. 2011;56(2):166-170.

16. Barros TEP, Campolongo GD, Zanluqui T, et al. Facial trauma in the largest city in Latin America, São Paulo, 15 years after the enactment of the compulsory seat belt Law. Clinics (Sao Paulo). 2010;65(10):1043-1047.

17. Patrocínio LG, Patrocínio JÁ, Borba BHC, et al. Fratura de mandíbula: análise de 293 pacientes tratados no Hospital de Clínicas da Universidade Federal de Uberlândia. Rev Bras Otorrinolaringol. 2005;71(5):560-565.

18. Minas Gerais. Deliberação CIB-SUS/MG $n^{\circ} 1.844$, de 21 de maio de 2014. 2016 